\title{
EKSPLOITASI ANAK MELALUI AKUN INSTAGRAM (ANALISIS WACANA KRITIS PRAKTEK SHARENTING OLEH SELEBGRAM ASHANTY \& RACHEL VENYA)
}

\author{
Merry Fridha Tri Palupi', Rahmat Edi Irawan ${ }^{2}$ \\ 'Universitas 17 Agustus 1945 Surabaya, \\ Jl. Semolowaru 45 Surabaya \\ 2Universitas Bina Nusantara Jakarta, \\ Jl. KH. Syahdan No 9 Palmerah Jakarta Barat \\ Email: ${ }^{1}$ merry_rafi@yahoo.co.id
}

\begin{abstract}
ABSTRAK
Praktek sharenting seringkali ditemui di akun instagram seseorang demikian pula dengan selebgram Ashanty dan Rachel Venya. Praktek sharenting ditandai dengan kerapnya orang tua membagi foto atau video anaknya ke media sosial. Penelitian ini menggunakan Analisis Wacana Kritis model Teun A. Van Dijk dan dari perspektif teoritis akan digunakan teori Szikoanalisis dari De Leuze \& Guatari. Szikoanalisis, di ibaratkan sebagai sebuah mesin hasrat yang terus bergerak, selalu diproduksi dan direproduksi untuk memuaskan subyek. Hasil penelitian menunjukkan bahwa pada analisis wacana teks (level mikro, superstruktur hingga makro) kedua selebgram ini memanfaatkan kelucuan dan kecerdasan anak mereka demi publisitas melalui foto, caption maupun tagar di instagram. Pada level kognisi Sosial, peneliti menganalisis bahwa praktek sharenting tidak didasari pada pemahaman akan literasi media akan data privasi. Hasil analisis pada level konteks sosial memperlihatkan bahwa praktek sharenting dapat berujung pada eksploitasi anak karena orang tua mendapatkan keuntungan secara finansial dari endorse sebuah produk/jasa yang menggunakan anaknya menjadi model iklan. Di sisi lain masyarakat tidak menganggap kegiatan sharenting sebagai bentuk eksploitasi dan malah memberi dukungan positif terhadap foto atau video yang diunggah ke dua selebgram tersebut.
\end{abstract}

Kata Kunci: Eksploitasi Anak, Analisis Wacana Kritis, Sharenting, Selebgram.

\begin{abstract}
Sharenting practices are often found on someone's Instagram account as well as Ashanty and Rachel Venya's celebrities. Sharenting practice is characterized by how often parents share their child's photos or videos on social media. This research uses the Critical Discourse Analysis of Teun A. Van Dijk's model and from a theoretical perspective will use the theory of Szikoanalysis from De Leuze \& Guatari. Szikoanalysis, described as an engine of desire that is constantly moving, is always produced and reproduced to satisfy the subject. The results showed that the analysis of text discourse (micro level, superstructure to macro) both of these celebrities used the humor and intelligence of their children for publicity through photos, captions and hashtags on Instagram. At the level of social cognition, researchers analyze that sharenting practices are not based on an understanding of media literacy in privacy data. The results of the analysis at the level of the social context show that sharenting practices can lead to child exploitation because parents benefit financially from endorse a product / service that uses their children to be an advertising model. On the other hand the community does not consider sharenting activities as a form of exploitation and instead provides positive support for photos or videos uploaded to the two programs.
\end{abstract}

Keywords: child exploitation, critical discource analysis, sharenting, celebgram 


\section{A. PENDAHULUAN}

Praktek sharenting seringkali ditemui pada akun instagram seseorang yang telah memiliki anak. Demikian juga selebgram yang aktif berselancar di dunia maya dan memiliki kekuatan sebagai influencer. Praktek sharenting dilakukan dengan cara mengunggah foto-foto atau video tumbuh kembang anak bahkan sebelum si anak lahir ke dunia (seperti foto hasil USG atau foto dimasa kehamilan), hingga tahap tumbuh kembang anak. Dengan seringnya selebgram membagi momen perkembangan anak, maka sangat memungkinkan akan membawa status anaknya menjadi selebgram anak.

Berbagai motif orang tua ditemukan saat mereka melakukan praktek sharenting salah satunya adalah agar anaknya menjadi terkenal (Putra \& Febrina, 2016). Tidak dapat dipungkiri bahwa segala hal mengenai kehidupan selebgram begitu menarik perhatian followernya. Maka anak selebgram juga akan menjadi pusat perhatian sebagai imbas dari status orang tuanya. Menjadi selebgram bagi bayi maupun anak kecil tentu saja bukan pilihan pribadinya, sebab anak belum memiliki kemampuan dalam menggunakan media sosial, maka dapat dikatakan bahwa orang tuanya lah yang memiliki kendali.

Profesi selebgram saat ini menjadi dambaan banyak orang, sebab dengan menjadi selebgram tentu saja seseorang akan memiliki penghasilan dari hasil endorse sebuah barang atau jasa. Untuk itu seorang selebgram akan selektif dalam memilih foto/video, karena bagi mereka konten yang disukai follower adalah tujuan utama. Istilah selebgram sendiri saat ini menjadi dikenal publik. Selebgram berarti selebriti di instagram atau dapat dikatakan bahwa selebgram adalah publik figur di media sosial instagram. Seseorang dapat dikatakan selebgram apabila telah memiliki follower mulai dari ratusan ribu hingga jutaan pengikut.

Selebgram bisa berasal dari pesohor dengan latar belakang artis ataupun bukan artis namun memiliki banyak pengikut di instagram. Berbagai penelitian tentang selebgram telah banyak dilakukan, diantaranya sakinah yang menganalisis kategori selebgram yaitu tidak hanya berdasarkan jumlah pengikut, jumlah likes dan komentar pada konten yang diunggah saja tapi juga bagaimana kemudahan nama akunnya muncul di bidang pencarian (Sakinah, 2018).

Ketenaran selebgram akan membawanya menjadi influencer yang memiliki pengaruh terhadap para pengikutnya. Demikian juga dengan praktek sharenting yang kerap dilakukan tentu akan di ikuti oleh pengikutnya. Kata atau istilah sharenting sendiri merupakan perpaduan kata share yang artinya berbagi, dan parenting yang berarti menjadi orang tua. Maka dapat diartikan bahwa sharenting adalah fenomena dimana orang tua membagi foto atau video anaknya ke media sosial seperti facebook, instagram maupun youtube.

Sebagai platform berbagi foto, pengguna instagram memiliki tujuan untuk mengekspresikan dirinya demi memenuhi kepuasan diri dengan cara mengunggah foto dan video (Bimo, 2017). Dan seiring dengan berjalannya waktu, saat ini terjadi pergeseran pemanfaatan instagram salah satunya adalah sebagai media bisnis. Dimana hal ini dikarenakan adanya perkembangan tren pasar sehingga pengguna dituntut untuk memiliki fitur yang unik agar akunnya banyak di lihat pengguna instagram lain (Verawati, 2016). Melihat perubahan pengunaan instagram tersebut maka para selebgram akan berlombalomba menyuguhkan konten yang menarik termasuk membagikan foto atau video anak mereka.

Praktek sharenting cukup marak dilakukan oleh orang tua di hampir semua negara. Dalam penelitian Anna Brosch praktek sharenting merupakan praktik yang lazim dilakukan oleh orang tua di Polandia. Dari 168 orang tua yang menjadi narasumber dalam penelitiannya menyatakan bahwa mereka kerap melakukan aksi sharenting (Brosch, 2016). Demikian juga penelitian Fox 
\& Hoy yang dilakukan di Amerika Serikat. Sebagai negara maju, undang-undang privasi daring sebenarnya telah diluncurkan pada tahun 1998, enam tahun sebelum peluncuran media sosial facebook, namun aksi sharenting masih tetap marak dilakukan oleh orang tua. Dari 15 ibu berusia 24-40 tahun yang diwawancara, mereka mengakui aktif menggunakan media sosial dimana saja, dan kerap melakukan aksi sharenting sebagai sarana membagi kebahagian dan bertukar informasi dengan para followernya (Fox \& Hoy, 2019).

Di Indonesia sendiri belum ada undang-undang yang mengatur tentang hal tersebut. Namun seperti telah dijelaskan diatas, terdapat beberapa negara maju seperti Amerika dan Prancis yang mengatur distribusi sebuah foto/video dan telah memiliki payung hukum berupa undangundang. Berikut undang-undang di Prancis yang berbunyi: "Barang siapa mempublikasikan dan mendistribusikan foto/video seseorang tanpa seizin dari yang bersangkutan dapat dikenakan hukuman penjara hingga 1 tahun atau denda sebesar 4500 Euro" (Dewi Widya Ningrum, Kompas. com 19 September 2016). Tentu saja undang-undang ini juga bisa dikenakan pada orang tua yang dengan sengaja membagi foto atau video anaknya ke media sosial terlebih dengan alasan mendapatkan keuntungan finansial. Undang-undang yang mengatur tentang pendistribusian foto/video di Prancis tersebut dapat meminimalisir ketidaknyamanan seseorang karena privasinya disebarluaskan di media sosial.

Ketiadaan undang-undang di Indonesia yang mengatur hal tersebut, disertai dengan ketidakmampuan akan literasi media, membuat orang tua merasa bahwa membagikan foto anaknya ke media sosial adalah sesuatu hal yang biasa, karena beranggapan bahwa anak adalah miliknya, dan bagian dari dirinya. Dan para selebgram akan bangga bila foto-foto tersebut mendapatkan perhatian positif dari masyarakat. Hal inilah yang disebut sebagai kesadaran palsu yaitu sebuah kesadaran yang diatur oleh sebuah kekuasaan yang sangat besar. Kesadaran palsu merupakan hegemoni dari kelas yang berkuasa untuk mempropagandakan sebuah ideologi yang begitu kuat sehingga kelas bawah tidak menyadari bahwa sebenarnya mereka sedang dieksploitasi dan menjadi korban (Sari, 2015).

Kesadaran palsu ini dipertajam oleh hasrat manusia yang terus diproduksi oleh sebuah mesin yang disebut oleh Deleuze \& Gauttari sebagai mesin hasrat. Mesin hasrat akan melalui self-production dan reproduksi hawa nafsu (Deleuze \& Gauttari, 1977). Mesin inilah yang akan menggerakkan peradaban manusia yang selalu ingin terlihat berbeda dari lainnya, dan terlihat lebih unggul demi menyenangkan hawa nafsu. Fenomena di atas menarik perhatian peneliti sehingga peneliti merumuskan masalah penelitian ini yaitu :"Bagaaimana wacana Eksploitasi Anak pada Praktek Sharenting oleh Selebgram Ashanty \& Rachel Venya melalui Akun Instagram?". Dimana penelitian ini bertujuan untuk mengetahui: "Wacana Eksploitasi Anak pada Praktek Sharenting oleh Selebgram Ashanty \& Rachel Venya melalui Akun Instagram".

Penggunaan teori szikoanalisis yang dirumuskan oleh Deleuze \& Gauttari untuk menganalisis eksploitasi anak melalui akun instagram yang dilakukan oleh selebgram dalam melakukan praktek sharenting. Peneliti mengutip perkataan Yasraf Amir Piliang yang mencoba menafsirkan pemikiran Deleuze dan Gauttari bahwa hasrat atau hawa nafsu tidak akan pernah terpenuhi oleh karena itu hasrat akan selalu diproduksi oleh sebuah mesin yang disebut sebagai mesin hasrat (desiring machine) (Piliang, 2003).

Deleuze dan Gauttari mengatakan bahwa dalam diri seseorang akan selalu ada hasrat. Hasrat akan selalu diproduksi dan direproduksi seseorang untuk memuaskan subyek. Menurut Lacan (dalam Faruk, 2014) hasrat berkaitan dengan keadaan kekurangan yang kemudian melahirkan ketidaksadaran secara utuh atau yang 
biasa disebut sebagai kesadaran palsu. Kesadaran palsu mengarahkan seseorang pada alienasi karena adanya tekanan pada struktur sosial.

Gilles Deleuze lahir di Prancis pada tahun 1925, sedangkan Fellix Gauttari adalah seorang psikiatris dan aktivis politik Prancis yang lahir pada 1930. Kedua sahabat ini menyumbangkan pemikirannya tentang szikoanalisis dimana hasrat merupakan penalaran ego (Indriani, 2018). Hasrat dalam pandangan Deleuze adalah:

"Mesin yang akan berputar bersama mesin lainnya. Mesin akan digerakan oleh mesin yang lain. Mesin akan terhubung dan saling membutuhkan. Mesin layaknya sebuah organ yang akan terhubung dengan sumber energi mesin sehingga menghasilkan aliran yang akan menginterupsi lainnya" (Deleuze, 1977).

Hasrat ingin dipuji dengan terus melakukan sharenting akan berujung pada eksploitasi anak. Eksploitasi terjadi karena ada hubungan yang tidak seimbang antara superordinasi dengan subordinasi, dimana orang tua berada pada posisi superordinasi sedangkan anak pada posisi subordinasi. Ketergantungan antara anak terhadap orangtua yang menyebabkan orang tua meyakini bahwa anak mereka milik mereka seutuhnya (Pebriani, Kebayantini dan Astika, 2016).

Dalam kajian tentang tubuh, dikenal mengenai konsep tubuh. Sejatinya otonomi tubuh adalah bersifat sistematis dan berkelanjutan dan selayaknya tidak dijajah oleh siapapun (termasuk orang tua kandungnya) (Benedicta, 2011). Pemikiran Deleuze dan Gauttari digunakan dalam penelitian ini karena peneliti melihat adanya hasrat untuk mengeksploitasi anak melalui praktek sharenting. Dimana hasrat tersebut dikarenakan adanya keinginan dari orang tua akan adanya pengakuan terhadap identitas diri yang berbeda dibanding dengan orang lain yang dianggap sebagai hal yang menyenangkan. Szikoanalisis melihat bahwa perilaku manusia adalah kehendak bebas yang tidak terikat oleh suatu aturan tertentu, namun di balik itu ada hasrat yang diproduksi tanpa kendali.

\section{B. TINJAUAN PUSTAKA}

Penelitian tentang praktek sharenting telah beberapa kali dilakukan oleh peneliti baik didalam maupun diluar negeri, namun peneliti belum menemukan penelitian sejenis yang menggunakan analisis wacana kritis. Beberapa penelitian tersebut digunakan peneliti untuk memperkaya penelitian ini.

Penelitian pertama ditulis oleh Karen Verswijvel dkk dengan judul Sharenting, is it a good or a bad thing? Understanding how adolescents think and feel about sharenting on social network sites. Penelitian ini menggunakan metode metode campuran yaitu kuantitatif dengan model regresi dan agar hasil lebih mendalam peneliti menggunakan metode penelitian kualitatif dengan Focus Group Discussion. Sedangkan teori yang digunakan adalah teori manajemen kesan. Hasil penelitian menunjukkan setidaknya ada empat motif yang dilakukan oleh orang tua dalam melakukan praktek sharenting, yaitu: motif kesenangan, motif sosial, motif mengarsip informasi dan motif berbagi informasi. Dengan 46 remaja yang menjadi informan mengatakan bahwa seharusnya orang tua tetap harus menghargai hak privasi mereka.

Penelitian tentang sharenting yang kedua dilakukan oleh Stacey B. Steinberg dari University of Florida Levin College of Law dengan judul penelitian Sharenting: Children's Privacy in the Age of Social Media. Penelitian ini mengeksplorasi potensi hukum dan solusi dari praktik sharenting yang dilakukan oleh banyak orang tua. Penelitian ini menggunakan metode kualitatif dan teori yang digunakan adalah manajemen informasi. Hasil penelitian merekomendasikan bahwa praktek sharenting harus ditolak karena Informasi yang dibagikan di Internet memiliki potensi untuk membuka informasi sang anak yang bertahan seumur hidup. Artinya, semua foto/video atau informasi apapun yang telah di unggah orang tua dimedia sosial akan 
terungkap ke publik dan jejak digitalnya akan sulit terhapus. Masalah ini cukup serius sehingga harus ada perlindungan terhadap hak privasi anak.

\section{METODE}

Penelitian ini menggunakan metode penelitian kualitatif. Penelitian kualitatif fokus pada konsep atau fenomena tunggal (Creswell, 2016). Sedangkan paradigma penelitian ini berpijak pada paradigma kritis, dimana menurut Creswell, penelitian kritis memiliki agenda untuk perubahan sosial. Paradigma kritis diambil dari pemikiran Marxis. Teori kritis menentang pemikiran teori tradisional. Teori kritis dipercaya akan dapat berkontribusi dalam membangkitkan kesadaran kritis masyarakat. Para ahli yang berpijak pada paradigma kritis umumnya tertarik dengan isu-isu masyarakat yang berada pada kondisi tertindas, kaum-kaum termarjinal dan turut mempromosikan emansipasi masyarakat (Ruliana\&Lestari, 2019).

Seperti layaknya penelitian berparadigma kritis, maka secara praktis penelitian ini bermanfaat untuk menggugah kesadaran para selebgram atau orangorang yang aktif menggunakan media sosial agar lebih menghargai privasi seseorang walaupun secara biologis itu adalah anaknya sendiri serta tidak melakukan praktek sharenting yang mengarah pada eksploitasi anak. Secara teoritis, penelitian ini bermanfaat untuk menambah khasanah kajian analisis wacana kritis di media sosial seputar isu-isu kontemporer di bidang parenting.

Sedangkan jenis penelitian ini yaitu penelitian yang akan menganalisis isi media dengan menggunakan analisis wacana. Analisis wacana digunakan untuk membedah eksploitasi anak dalam akun instagram selebgram. Peneliti memilih analisis wacana Van dijk untuk memformulasi elemen-elemen wacana yang ada. Analisis wacana Van Dijk dipilih sebab model analisis wacana Van Dijk menyatakan bahwa wacana tidak cukup bila hanya didasarkan pada teks semata, karena teks merupakan hasil dari suatu proses produksi yang harus diamati. Analisis wacana model Teun A. Van dijk menyatakan bahwa di balik sebuah teks ada sebuah kognisi sosial yang dibangun (Eriyanto, 2001).

Dalam analisis wacana model Van dijk, wacana di bagi dalam tiga tingkatan, yaitu teks yang terdiri dari (struktur mikro, superstruktur, dan struktur makro), kognisi sosial dan konteks sosial (Sobur, 2009: 73). Pada level teks yang akan diteliti adalah bagaimana sebuah struktur teks dan strategi wacana dipakai untuk menegaskan sebuah tema (Yana, 2015). Teks pada stuktur makro adalah struktur suatu teks yang diamati dengan melihat topik dari suatu peristiwa. Superstruktur yaitu struktur wacana yang menghubungkan suatu teks secara utuh, sedangkan struktur mikro yaitu makna wacana yang dilihat dari unit terkecil seperti kata atau kalimat. Tahapan kedua adalah kognisi sosial, pada level ini akan dilihat bagaimana sebuah kalimat diproduksi oleh produsen sesuai dengan kognisi sosialnya. Dan tahap ketiga adalah konteks sosial yaitu bagaimana sebuah teks dihubungkan dengan struktur sosial yang berkembang di masyarakat (Eriyanto, 2001).

Analisis wacana kritis merupakan metodologi yang mempelajari bahasa dan teks yang mengacu pada ilmu linguistik, teori sastra dan studi budaya, filsafat bahasa, sosiologi, psikologi dan ilmu komunikasi. Dengan demikian dapat dikatakan analisis wacana kritis merupakan kajian multi disipliner (Aini \& Widodo, 2018). Sementara itu unit analisis dalam penelitian ini yaitu enam foto dari subyek penelitian, artinya masing-masing subyek penelitian, peneliti ambil tiga foto yang memperlihatkan wacana eksplotasi anak di instagram. Agar data yang diperoleh valid maka penulis menggunakan trianggulasi. Trianggulasi yaitu memeriksa bukti-bukti yang berasal dari sumber dan menggunakannya untuk membangun justifikasi tema-tema secara koheren (Creswell, 2018). Trianggulasi dalam penelitian berguna untuk mengecek kebenaran dan juga memperkaya data (Moleong: 2004). 


\section{TEMUAN}

Dalam penelitian ini akan menganalisis praktek sharenting yang dilakukan dua orang selebgram yaitu Ashanty yang berprofesi sebagai penyanyi terkenal, istri dari Anang Hermansyah yang sangat aktif di media sosial instagram. Ashanty memiliki 19,7 juta pengikut di instagram. Setiap postingannya selalu disukai oleh puluhan ribu orang, dan dikomentari ratusan hingga lebih dari seribu followernya. Dengan banyaknya pengikut di instagram maka Ashanty layak disebut sebagai selebgram.

Wacana eksploitasi anak di instagram juga dianalisis pada akun instagram Rachel Venya, seorang selebgram yang memang mendedikasikan dirinya pada media sosial berbagi foto dan video. Rachel Venya

memiliki pengikut di instagram sebanyak 3,9 juta orang. Dengan profesinya sebagai selebgram, Rachel Venya selalu ditunggu followernya untuk membagi foto/video. Dalam sekali posting Rachel Venya bisa mendapat like dan komentar hingga ribuan. Dengan demikian maka bukan hal yang berlebihan bila Rachel Venya disebut sebagai selebgram.

Dalam penelitian ini peneliti mengambil masing-masing tiga foto dari kedua subyek penelitian yang menggambarkan praktek sharenting. Foto-foto tersebut diambil acak oleh peneliti, Berdasarkan hasil pengamatan peneliti, kedua subyek penelitian kerap membagikan foto maupun video anak-anak mereka. Berikut Foto-foto yang menjadi unit analisis:
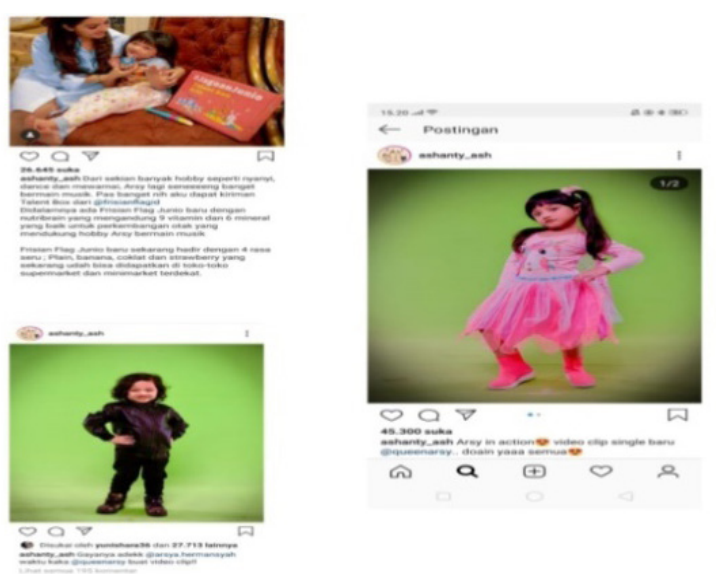

Gambar 1. Kolase Praktek Sharenting Instagram Ashanty dan Rachel Venya

Sumber: Instagram Ashanty \& Rachel Venya.

\section{E. BAHASAN}

\section{Analisis Teks}

Dalam menganalisis level teks, peneliti membagi tiga lapisan teks yaitu mikro, makro dan superstruktur. Pada struktur mikro peneliti akan menganalisis foto \& caption dari sisi semantik dan sintaksis. Pada struktur makro peneliti akan menganalisis dari sisi tematik dan pada superstruktur peneliti akan menganalisis dari sisi skematik. Setelah menganalisis teks, peneliti akan menganalisis level kognisi sosial dan dilanjutkan dengan menganalisis level konteks sosial. Sebelum melakukan analisis, peneliti telah mengelompokkan tiga tema dari caption yang di unggah kedua selebram, yang terdapat pada tabel 1 berikut ini: 
Tabel 1 Elemen Tematik

\begin{tabular}{l} 
Hal yang Diamati \\
\hline Topik Eksploitasi pada masa tumbuh kembang \\
anak. \\
1. Ashanty menulis caption : Gayanya adek @ \\
Arsya Hermansyah waktu kaka @Queenarsy \\
buat video Clip!!
\end{tabular}

2. Rachel Venya menulis caption: "hari ini melukis es krim" gambar emoticon es krim selebgram

1. Ashanty menulis caption:"Arsy in action. Video clip single baru @quenarsy...doain ya teman-teman.

2. Rachel Venya menulis caption:"MasyaAllah Tabarakallah. Sebentar lagi kita ketemu. Semua doa baik untuk kamu adik\#31weekspregnant
Topik Eksploitasi menjadikan anak sebagai

\section{Temuan Data}

Kedua foto tersebut menggambarkan tumbuh kembang anak dari kedua subyek penelitian.

Pada instagram Ashanty mempost foto arsya, anak laki-lakinya yang kini berusia 3 tahun yang ganteng dan lucu serta pintar bergaya di depan kamera.

Sedang pada instagram Rachel Venya, dia memposting anak laki-lakinya yang berusia 2 tahun dan telah pintar menggambar es krim.

Pada foto yang diupload oleh Ashanty, ia hendak menunjukkan bahwa anaknya telah menjelma menjadi artis cilik dan ungkapan mohon doa dukungan netizen untuk kesuksesan si anak. Foto ini mendapat 26.663 like dan 198 komentar. Pada foto yang diposting oleh Rachel Venya, terdapat foto hasil USG 3 dimensi dari sang anak yang masih berada dalam kandungan. Kalimat berseru menyebut nama Tuhan, dan sapaan kepada calon bayi serta informasi kepada netizen bahwa saat ini ia sedang mengandung 31 minggu. Postingan ini mendapat 515.423 like dan komentar sebanyak 2256.

Topik Eksploitasi anak melalui endorse

Foto yang diupload oleh Ashanty merupakan

1. Ashanty menulis: Dari sekian banyak hobi seperti nyanyi, dance dan mewarnai, Arsy lagi seneng banget bermain musik. Pas banget nih aq dapat kiriman Talent Box dari @frisianflagid. Didalamnya ada Frisian Flag Junio baru. Dengan nutribrain yang mengandung 9 vitamin dan 6 mineral yang baik untuk perkembangan otak yang mendukung hobby arsy bermain musik. Frisian Flag Junio baru sekarang hadir dengan 4 rasa seru: plain, banana,cokelat dan strawberry yang sekarang udah bisa didapatkan di toko-toko supermarket dan minimarket terdekat. Untuk info endorse produk yang menggunakan Arsy anaknya menjadi bintang iklan. Sedangkan foto yang diupload Rachel Venya merupakan promosi usaha pakaian bayi miliknya dan menggunakan anaknya untuk menjadi model iklan.

Nampak kalimat pada caption sudah dikemas sedemikian rupa dan menunjukkan promosi produk. Dengan kelucuannya kedua anak tersebut, maka iklan promosi frisan flag oleh Arsy (anak Ashanty mendapat 226.663 like dan 198 komentar. Sedangkan promosi pakaian bayi yang dilakukan Biru (anak Rachel Venya) disukai oleh hampir dari 400.000 netizen dan 887 komentar netizen. selanjutnya, yuk follow @frisianflagid \#jagoanjunio\#frisianflag.

2. Sedangkan Rachel Venya menulis caption:"Mau nyapa cewe cantik tapi salting guys. PS:@Mahikacatalog sudah upload sizechart, catalog dan pricelist yaa ibuk2 jgn sampe kehabisan nanti jd bs pikirin dr skrg. Biru wearing Bamby playsuit in turquoise Shiren wearing Shelby romper in yellow stripe 
Pada level mikro yang terdiri dari semantik dengan elemen latar, detail dan maksud. Hasil analisis peneliti menunjukkan bahwa:

a. Latar, yang merupakan rangkaian peristiwa yang terjadi pada teks menggambarkan situasi akan kebanggaan orang tua terhadap anak-anaknya disemua unggahan kedua selebgram.

b. Detail, pada elemen ini kedua selebgram memberikan informasi secara detail mengenai anak-anaknya dalam setiap postingan anak-anak mereka. Misalkan Rachel Venya yang menceritakan tentang usia si bayi dalam kandungan, dan juga tumbuh kembang anak pertamanya. Juga Ashanty yang menceritakan kecerdasan serta kelucuan kedua anaknya.

c. Maksud, pada elemen maksud peneliti menganalisis bahwa kedua selebgram tidak merasa bahwa praktek sharenting yang dilakukan telah mengarah pada bentuk eksploitasi karena telah menjadikan anak menjadi model iklan yang menghasilkan uang, seperti dalam wawancara dengan Rachel Venya berikut ini:

"Kita upload foto anak itu tujuannya hanya berbagi kebahagiaan dan untuk menyimpan foto sebagai kenangkenangan aja".

Pada level mikro selanjutnya terdapat elemen sintaksis yang terdiri dari koherensi, bentuk kalimat, kata ganti, stilistik dan retoris. Dengan hasil analisis berikut ini:

a. Koherensi

Pada elemen koherensi atau kata hubung dapat dilihat pada caption Ashanty:

"Dari sekian banyak hobi seperti nyanyi, dance dan mewarnai, Arsy lagi seneng banget bermain musik. Pas banget nih aq dapat kiriman Talent Box dari @frisianflagid. Didalamnya ada Frisian Flag Junio baru. Dengan nutribrain yang mengandung 9 vitamin dan 6 mineral yang baik untuk perkembangan otak yang mendukung hobby arsy bermain musik.Frisian Flag Junio baru sekarang hadir dengan 4 rasa seru: plain, banana, cokelat dan strawberry yang sekarang udah bisa didapatkan di toko-toko supermarket dan minimarket terdekat. Untuk info selanjutnya, yuk follow @frisianflagid \#jagoanjunio\#frisianflag".

Pada kata sambung dengan yang dilanjutkan kata nutribrain, terlihat bahwa Ashanty hendak menyampaikan bahwa kecerdasan dan talenta anaknya didapat karena anaknya minum susu dengan merk frisianlag yang mengandung multi vitamin yang bagus untuk otak.

b. Bentuk Kalimat

Pada Elemen bentuk kalimat, terdapat ajakan kepada follower untuk membeli atau menggunakan barang yang di iklankan. Bentuk kalimat membujuk sangat terlihat dalam unggahan tersebut. Dan pada postingan lain dapat dilihat upaya ke dua selebgram ini membawa hubungan agar lebih dekat dengan followernya.

c. Kata Ganti

Pada Elemen kata ganti, hasil analisis peneliti melihat pada kalimat Rachel Venya:

"Mau nyapa cewe cantik tapi salting guys.PS:@Mahikacatalog sudah upload sizechart, catalog dan pricelist yaa ibuk2 jgn sampe kehabisan nanti jd bs pikirin dr skrg. Biru wearing Bamby playsuit in turquoise Shiren wearing Shelby romper in yellow stripe.

Pada kalimat diatas kata ganti untuk follower Rachel Venya yang merupakan ibu muda digunakan kata guys. Kata guys saat ini sangat familier sebab sering digunakan oleh selebgram dan youtuber sebagai sapaan yang bermakna teman akrab. Maka peneliti menganalisis bahwa Rachel Venya menganggap followernya sebagai teman akrab yang akan diberi cerita tentang kelucuan anaknya. 
d. Stalistik

Pada elemen stalistik atau pemilihan kata bisa dilihat bahwa Ashanty dan Rechel Venya menggunakan kalimat yang selalu membanggakan anakanak mereka. Terkadang pemilihan kalimat dalam balut doa seperti Kalimat yang disampaikan Rachel Venya dalam unggahan foto hasil USG bayi dalam kandungannya, "Masya Allah, Tabarakallah" atau Ashanty dengan kalimat :" Video clip single baru @ quenarsy...doain ya teman-teman". Dalam dua kalimat ini dapat dilihat bahwa kedua selebgram ini ingin mengajak followernya layaknya saudara atau teman yang turut mendoakan anakanak mereka.

e. Retoris

Pada elemen retoris terlihat penekanan pada tingkah laku lucu si anak seperti disampaikan Rachel Venya pada kalimat:"Mau nyapa cewek malu guys". Kalimat ini tentu tidak menggambarkan kondisi sebenarnya. Melainkan sebuah metafora, sebab si anak masih berusia dua tahun. Usia yang terlalu dini untuk mengenal lawan jenis. Metafora dilakukan agar caption lebih menarik dalam melengkapi foto.

Pada Struktur Makro, peneliti akan menganalisis dari tema. Tema yang penulis lihat dari gagasan kedua selebgram dalam melakukan praktek sharenting peneliti kelompokkan dalam tiga tema eskploitasi, yaitu eksploitasi tumbuh kembang anak. Pada tema ini terlihat bahwa kedua narasumber telah mengunggah foto sang anak mulai dari dalam kandungan hingga si anak lahir kedunia. Tema kedua adalah eksploitasi dengan menjadikan anak mereka sebagai selebgram. Hal ini dapat dilihat dari seringnya kedua narasumber melakukan praktek sharenting sehingga si anak menjadi lebih dikenal publik. Tema ketiga yaitu eksploitasi anak dengan menjadikan anak bintang iklan (endorser) sehingga menghasilkan uang.
Level terakhir adalah superstruktur, dimana peneliti akan menganalisis dari sisi skematik. Pada level ini peneliti hendak melihat alur dari praktek sharenting yang dilakukan kedua narasumber. Dari analisis yang dilakukan peneliti terlihat akan alur yang di unggah narasumber yaitu kegiatan sehari-hari anak-anak narasumber. Ke dua narasumber memanfaatkan kelucuan anakanak mereka dan hal ini berhasil mencuri perhatian netizen sehingga setiap aksi sharenting selalu mendapatkan respon hangat berupa komen dan like.

Pada level teks diatas peneliti melihat bahwa hasrat ingin dipuji dan eksistensi diri melatarbelakangi kedua selebgram dalam melakukan praktek sharenting. Hasrat tersebut layaknya sebuah mesin yang terus diproduksi dan reproduksi untuk mendapatkan pengakuan dari khalayak. Kedua selebgram tidak berfikir jauh, apakah praktek sharenting yang dilakukan memiliki dampak positif atau negatif kepada anaknya dimasa depan.

Hasil analisis peneliti sejalan dengan hasil penelitian dari Verswijvela, Walrave, Hardies dan Heirmana yang menyatakan bahwa ketika anak beranjak remaja, ada dua kemungkinan tanggapan anak terhadap praktek sharenting yang dilakukan orang tuanya. Tanggapan lebih positif akan diberikan pada remaja yang memiliki kedekatan dengan orang tuanya dan memiliki suasana keluarga yang hangat. Sedangkan pada remaja yang kurang memiliki kedekatan dengan orang tua, remaja merasa bahwa sharenting yang dilakukan orang tuanya tidaklah bermanfaat dan tidak selaras dengan kondisi dalam keluarga yang sesungguhnya (Verswijvela, Walrave, Hardies dan Heirmana, 2019). Jadi bila disimpulkan bahwa praktek sharenting akan menimbulkan perasaan tidak nyaman pada anak dalam kondisi-kondisi tertentu.

\section{Analisis Wacana Kognisi Sosial}

Pada level kognisi sosial penulis akan menganalisis dari sisi pada kesadaran narasumber dalam melakukan praktek sharenting. Hasil analisis yang penulis 
temukan menujukkan bahwa dua narasumber tidak menyadari bahwa praktek sharenting yang kerap dilakukan merupakan kesadaran palsu. Hal ini seperti disampaikan Ashanty dalam wawancara berikut ini:

"Duh mbak kejauhan deh mikirnya, kita gak mikir kesitulah. Cuma pingin membagi kelucuan anak-anak aja. Jadi endorser juga gak maksa, kalau anaknya mau. Tidak juga saya gak maksa.."

Pada level kognisi sosial narasumber tidak memahami bahwa dengan menerima endorse berarti kedua selebgram ini telah memperkerjakan anak dibawah umur. Maka peneliti menganalisis bahwa perilaku sharenting yang dilakukan oleh kedua selebgram di atas tidak didasari pada pemahaman akan literasi media. Kedua selebgram menganggap bahwa anak mereka merupakan miliknya, bagian dari dirinya yang tidak terpisahkan. Kesadaran palsu yang membelenggu diperlihatkan dengan rajinnya Ashanty dan Rachel Venya menjawab satu persatu pujian netizen dengan ucapan terimakasih. Kebanggaan sebagai orang tua yang memiliki anak lucu dan pintar disampaikan dengan terus memposting proses tumbuh kembang anaknya. Hasrat ingin dipuji dan mengambil keuntungan secara finansial dilakukan tanpa adanya kesadaran penuh bahwa yang dilakukannya merupakan bentuk eksploitasi terhadap buah hatinya.

Secara finansial kedua selebgram ini mendapatkan keuntungan ketika si anak menjadi selebgram. Karena dengan demikian maka uang akan datang bersamaan dengan tawaran endorse sebuah produk/jasa. Menjadikan anak sebagai selebgram merupakan kebanggaan tersendiri bagi orang tua karena artinya anak mereka menjadi pusat perhatian yang disukai oleh banyak orang. Kedua subyek penelitian ini, tidak menyadari bahwa anak mereka merupakan dua orang berbeda yang bukan dirinya. Ketiadaan undangundang yang mengatur masalah sharenting membuat kedua selebgram tersebut terus menerus melakukan hal tersebut dan tidak menyadari bahwa hal ini merupakan bagian dari eksploitasi terhadap anak.

Melihat dampak negatif dari sharenting yang dilakukan secara berlebihan maka selayaknya ada aturan yang mengatur mengenai praktek sharenting. Himbauan keras terhadap sharenting disampaikan oleh Stacey B. Steinberg dalam rekomendasi hasil penelitiannya dengan menyatakan, kegiatan sharenting harus ditolak sebab informasi yang dibagikan orang tua di media sosial memiliki potensi menjadi jejak digital yang akan bertahan seumur hidup. Masalah ini cukup serius karena dapat menjadikan anak menjadi tidak nyaman karena privasinya diketahui publik, untuk itu anak wajib mendapatkan perlindungan terhadap data pribadi mereka sebelum mereka beranjak dewasa (Steinberg, 2017).

\section{Analisis pada Level Konteks Sosial}

Pada level ini peneliti akan menganalisis komponen teks yang mengacu pada konteks sosial masyarakat dimana teks dibentuk. Di level ini, peneliti menganalisis bahwa foto-foto yang di unggah oleh kedua subyek penelitian pada dasarnya merupakan rangkaian pesan yang berisi kebanggaan orang tua terhadap anakanaknya. Dalam kehidupan bermasyarakat kondisi ini dianggap hal yang wajar.

Pada konteks sosial, praktek sharenting yang mengarah pada eksploitasi anak, tidak dipandang negatif oleh masyarakat. $\mathrm{Hal}$ ini terlihat dari dukungan netizen yaitu berupa komentar-komentar positif terhadap foto-foto yang di unggah kedua selebgram tersebut terhadap foto sang anak. Seperti komentar salah satu netizen dengan nama akun @unielucu: "Bunda sama anak sama-sama lucu @Ashanty". Banyaknya pujian mengindikasikan bahwa tindakan sharenting adalah hal yang lumrah. Hal ini akan menambah keyakinan bahwa sharenting bukanlah hal yang dilarang.

Ketidak mengertian orang tua terhadap bahaya dibalik pratek sharenting begitu banyak. Seperti yang penulis rujuk dari penelitian Dyer bahwa dikhawatirkan jejak digital akan berdampak pada anak yaitu 
menjadi korban dari berbagai kejahatan di dunia maya, seperti menjadi target cyberbullying, pencurian idetitas dan sexting (Dyer, 2018). Untuk menghindari bahaya yang mengintai dibalik praktek sharenting maka selayaknya orang tua harus menghormati privasi data sang anak, seperti disampaikan Gaëlle Ouvrein \& Karen Verswijvel bahwa orang tua wajib memahami batasan, mengenai jenis postingan apa yang bisa dibagikan di instagram, seberapa sering waktunya dan dengan siapa foto tersebut dibagikan (Ouvrein \& Karen, 2019). Seyogyanya mendistribusi foto/vodeo orang lain harus meminta ijin namun karena anak-anak mereka masih dibawah umur anak-anak belum memahami akan hal ini.

\section{F. KESIMPULAN}

Dari analisis wacana menggunakan model analisis Van Dijk yang dilakukan peneliti mengenai eksploitasi anak pada akun instagram Ashanty dan Rachel Venya, maka peneliti membuat simpulan bahwa: pada level Teks (analisis mikro, superstruktur hingga analisis makro) kedua subyek penelitian memanfaatkan kelucuan dan kecerdasan anak yang dikemas dalam foto, caption maupun tagar. Pada level kognisi Sosial hasil analisis peneliti melihat praktek sharenting yang dilakukan tidak didasari pada pemahaman akan literasi media. Hasrat ingin di puji dilakukan tanpa adanya kesadaran penuh bahwa yang dilakukannya telah mengarah pada bentuk eksploitasi terhadap buah hatinya. Pada level analisis konteks sosial hasil analisis memperlihatkan bahwa praktek sharenting yang berujung pada eksploitasi pada anak ini tidak dipandang negatif oleh masyarakat. Hal ini terlihat dari dukungan netizen yaitu berupa komentar-komentar positif terhadap fotofoto yang diupload kedua selebgram tersebut terhadap foto sang anak.

Dari hasil analisis peneliti, maka peneliti menghimbau kepada pemerintah untuk merumuskan undang-undang yang mengatur praktek sharenting yang dapat mengarah pada praktek eksploitasi terhadap anak di media sosial dan perlunya literasi media kepada orang tua.

\section{REFERENSI}

Amir, Piliang, Yasraf. 2003. Hipersemiotika Tafsir Cultural Studies atas Matinya Makna. Yogyakarta. Jalasutra.

Aini, Nurul \& Widodo, Pratomo. 2018. Critical Discourse Analysis of the Bombing Attack News: An Analysis of Teun A. van Dijk's Model. Advances in Social Science, Education and Humanities Research, volume 165. Atlantis Press. Diakses dari file:///D:/ISKI/25904607. pdf

Benedicta, Gabriella, Devi. 2011. Dinamika Otonomi Tubuh Perempuan: Antara Kuasa dan Negosiasi Tubuh. Masyarakat (Jurnal Sosiologi). Vol 6. Hal 141-156. Diakses dari file:/// D:/4963-9316-1-SM.pdf

Bimo, Mahendra. 2017. Eksistensi Sosial Remaja Dalam Instagram (Sebuah Perspeltif Komunikasi). Jurnal Visi Komunikasi. Volume 16. Hal 151 - 160

Brosch, Anna. 2016. When The Child Is Born Into The Internet: Sharenting as a Growing Trend among Parents on Facebook. The New Educational Review 43 (1): 225-235. DOI: 10.15804/tner.2016.43.1.19. Diakses dari https://www.researchgate.net/ publication/299601525_When_the_Child_is_Born_into_the_Internet_Sharenting_ as_a_Growing_Trend_among_Parents_on_Facebook

Creswell, Jhon W. 2018. Research Design. Pendekatan Metode Kualitatif, Kuantitatif dan Campuran. Edisi 4. Yogyakarta: Pustaka Pelajar. 
Deleuze, Gilles \& Gauttari, Felix. 1977. Anti-Oedipus, capitalism, and Schizophrenia. New York: Viking Press.

Dyer, Tobbi. 2018. The Effects of Social Media on Children. DJIM. Vol 14. Diakses dari file:/// D:/7855-14306-1-PB.pdf

Eriyanto. 2003. Analisis wacana. Yogyakarta: LkiS

Faruk. 2014. Pengantar Sosiologi Sastra. Edisi Revisi.Yogyakarta. Pustaka Pelajar.

Fox, Alexa, K \& Hoy, Marriea, Grubbs. 2019. Smart Devices, Smart Decisions? Implications of Parents' Sharenting for Children's Online Privacy: An Investigation of Mothers. Sage Journal. Diakses dari https://journals.sagepub.com/doi/10.1177/0743915619858290

Indriyani M.Y. 2018. Kepribadian Tokoh FahUtama dalam Novel Karya Nadjib Kartapati Z (Kajian Shizoanalisis Deleuze \& Gautari. Tesis Univesitas Negeri Surabaya. Tidak diterbitkan.

KBBI online diakses agutus 2019

Moleong, J. lexi. 2017. Metodologi Penelitian Kualitatif. Edisi Revisi. Bandung: Remaja Rosdakarya.

Ouvrein, Gaëlle \& Verswijvel, Karen. 2019. Sharenting: Parental adoration or public humiliation? A focus group study on adolescents' experiences with sharenting against the background of their own impression management. Journal Elsevier. Halaman 319327.Diakes dari journal homepage: www.elsevier.com/locate/childyouth

Pebriani, Putu, Fania, \& Kebayantini, Ni Luh, Nyoman, \& Astika, Ketut, Sudhana. 2016. Tukang Suun Anak-Anak: Bentuk Eksploitasi Orangtua Terhadap Anak (Studi Kasus di Pasar Badung, Denpasar-Bali. Jurnal Ilmiah Sosiologi (SOROT). Vol 1 No 1. Hal 1-14. Diakses dari https://ojs.unud.ac.id/index.php/sorot/article/view/20487

Putra, Afdal, Makkuraga \& Febrina, Annisa. Fenomena Selebgram Anak. Memahami Motif Orang Tua. 2019. Jurnal Aspikom. Vol 3 No 6. Halaman 1093-1108. Diakses dari http:// jurnalaspikom.org/index.php/aspikom/article/view/396/168

Ruliana, Poppy \& Lestari, Puji. 2019. Teori Komunikasi. Depok: Rajawali Press.

Sakinah. 2018. Selebgram:Meraih Popularitas melalui Cyberspace. Jurnal Etnografi Indonesia (Etnosia). Vol 3. Halaman 48-71. Diakses dari Sari, Purnama, Wulan. 2015. Konflik Budaya Dalam Konstruksi Kecantikan Wanita Indonesia (Analisis Semiotika Dan Marxist Iklan Pond's White Beauty Versi Gita Gutawa). Jurnal Komunikasi ISSN 20851979 Vol. 7, No. 2. Hal 198 - 206. Diakses dari file:///D:/ISKI/18-164-1-PB.pdf

Sobur, Alex. 2009. Analisis Teks Media. Yogyakarta: LKiS

https://www.researchgate.net/publication/327183222_Selebgram_Meraih_Popularitas_ melalui_Cyberspace

Steinberg, B Stacey. 2017. Sharenting: Children's Privacy in the Age of Social Media. Emory Law Journal.Vol. 66:839 Diakses dari https://scholarship.law.ufl.edu/cgi/viewcontent. cgi?article $=1796 \&$ context $=$ facultypub

Verawati, Noning. 2016. Pergeseran Pemanfaatan Instagram Sebagai Media Bisnis Online (Studi Kasus pada Akun @Schonehazle).Jurnal Ilmu Komunikasi.Vol 12 Hal 1-81. Diakses dari http://jurnal.ubl.ac.id/index.php/JIK/article/view/652

Yana, Dewi. 2015. Critical Discourse Analysis (CDA) of Sindo News Paper. Jurnal Dimensi. Vol 4 No 2.

Diakses dari https://www.journal.unrika.ac.id/index.php/jurnaldms/article/view/41/40 
Verswijvela, Karen .Walrave, Michel. Hardies, Kris. Heirmana, Wannes. 2019. Sharenting, is it a good or a bad thing? Understanding how adolescents think and feel about sharenting on social network sites. Journal Elsevier. Diakses dari https://www.sciencedirect.com/ science/article/pii/S0190740919303482?via\%3Dihub

https://inet.detik.com/konsultasi-cyberlife/d-3301360/bahaya-memposting-foto-anak-dimedia-sosial 